\title{
La escritora y sus detractores: \\ Clorinda Matto de Turner (1890-1895)
}

The writer and her detractors: Clorinda Matto de Turner (1890-1895)

Juan José Pacheco Ibarra'

Universidad Nacional Mayor de San Marcos. Lima, Perú

juan.pacheco@unmsm.edu.pe

\section{RESUMEN}

Este artículo estudia un periodo poco investigado de la vida de Clorinda Matto de Turner: los años de su apoyo al Gobierno de Andrés A. Cáceres y su actividad intelectual durante su vida en Lima.

Durante estos años Clorinda Matto fue víctima de excomuniones, censuras y críticas de sus detractores. Todas las actitudes hacia ella nos van dibujando una imagen a partir de los estereotipos que afectaban a las mujeres escritoras de la época y que se encuentran presentes en la prensa periódica.

El caso de Clorinda Matto nos ayuda a comprender cómo eran percibidas las mujeres que se dedicaban a la política en los años finales del siglo XIX.

\section{PALABRAS CLAVE}

Clericalismo, género, Lima, mujeres, prensa

\section{ABSTRACT}

This paper focuses on a little-known period of Clorinda Matto de Turner's life: her years of support for the government of Andrés A. Cáceres and her intellectual activity during the time she spent in Lima.

During those years, Clorinda Matto fell victim to excommunication, censorship, and the criticism leveled by her detractors. The positions taken against her paint a picture of the stereotypes affecting women writers of the time, which were reflected in the press of the period.

1 Es historiador y gestor cultural en la Municipalidad Metropolitana de Lima. Parque de la Exposición. El jardín de Lima (Munilibros) es su más reciente publicación. 
The life of Clorinda Matto helps us understand how women who engaged in politics during the late nineteenth century were perceived.

\section{KEYWORDS}

Clericalism, gender, Lima, women, press

\section{Introducción}

En el siglo XIX hicieron aparición en la escena las primeras generaciones de escritoras peruanas. Clorinda Matto de Turner fue una de ellas. Sus novelas tuvieron gran acogida; sin embargo, generaron gran polémica en el mundo intelectual del siglo XIX. Su posición frente a la Iglesia católica, su abierto apoyo al Gobierno de Andrés A. Cáceres y su enfrentamiento con escritores de la época le trajeron muchas dificultades que finalmente la condujeron al autoexilio en Argentina, donde falleció en 1910.

Los años en Lima fueron los más intensos en su vida política y literaria, pero también los menos estudiados. En este artículo abordaremos algunos aspectos de su vida entre 1890 y 1895, tratando de comprender cuál fue su situación como escritora en un ambiente dominado por hombres.

\section{Clorinda Matto de Turner en Lima}

Clorinda Matto llegó a Lima el 28 de febrero de 1877, para concurrir a las veladas literarias de Juana Manuela Gorriti. Posteriormente, regresó al Cusco, donde quedó viuda en 1881.

En setiembre de 1883 viajó a Arequipa para asumir la dirección del periódico La Bolsa. El ambiente conservador arequipeño y el bajo sueldo que recibía la alejaron de esta ciudad. Clorinda Matto le escribió a Ricardo Palma (1885) diciendo que era difícil vivir en ese lugar.

Aquí no se puede vivir: existe un espíritu de envidia tan marcado, y una prevención para todo lo que sea del Cusco, que las hace insoportables a los arequipeños tan fanfarrones y vanidosos ${ }^{2}$.

Como ha indicado Rocío Ferreira:

El 3 de junio de 1886, una vez que Andrés Avelino Cáceres sube a la presidencia, Clorinda Matto se traslada de Arequipa a Lima, donde residió por un periodo de nueve años. En este periodo, la escritora defendió con convicción el Partido Constitucional que dirigía el nuevo líder (Ferreira, 2006, p. 5).

2 Biblioteca Nacional del Perú, Archivo Ricardo Palma. Carta de Clorinda Matto a Ricardo Palma. 
Matto de Turner viajó a Lima con la esperanza de encontrar un lugar para llevar a cabo sus proyectos literarios y donde la sociedad conservadora no fuera tan agresiva con su obra. Desde ese momento, la relación de la escritora giraría en torno a dos grupos sociales considerados inferiores o menores de edad: las mujeres y los indígenas.

\section{El Perú llustrado (1889-1892)}

Clorinda Matto de Turner asumió la dirección del semanario El Perú Ilustrado el 1 de octubre de 1889. Durante esos años publicó Aves sin nido y se convirtió rápidamente en una de las novelas más leídas de la época.

En el número 172 de El Perú llustrado fue publicado el cuento «Magdala», del escritor brasileño Henrique Coelho Netto, que por su contenido polémico acerca de la vida de Jesucristo originó una ola de protestas entre los católicos en Lima y otras ciudades del Perú.

El 3 de setiembre de 1890, la Iglesia católica decretó la excomunión de El Perú llustrado. En las iglesias se ordenó a los feligreses no permitir la lectura de esta publicación en los hogares cristianos. En Arequipa se tomaron medidas más extremas. Como informa La Linterna:

[en] Arequipa, Cusco, Puno, etc., hicieron un auto de fe con el periódico de Bacigalupi y con el retrato de su directora la respetable señora Matto de Turner (La Linterna, 20 de setiembre de 1890).

En estas ciudades se organizaron meetings y reuniones donde se quemaron ejemplares de El Perú llustrado. La presión del poder eclesiástico y la población católica al final hizo ceder a los propietarios de esta publicación.

En el Cusco, se convocó una reunión en la Unión Católica de esa ciudad, para protestar y quemar El Perú Ilustrado y una efigie de la escritora. Luego, la multitud se dirigió a destruir la casa donde había nacido. Esto no ocurrió porque no se pudo identificar su residencia. El incidente fue tan grave que se pensó sacar en procesión a la imagen del Señor de los Temblores a manera de desagravio.

En julio de ese año, Peter Bacigalupi, propietario de El Perú llustrado, pidió disculpas y rogó al arzobispo que se retirara la excomunión. Esta actitud fue muy criticada por la prensa liberal, que consideraba a esto un ataque a la libertad de pensamiento y una intromisión de la Iglesia en asuntos públicos.

La excomunión produjo importantes pérdidas al semanario. Peter Bacigalupi, propietario del El Perú llustrado, ofrecía el semanario a 20 centavos, en lugar de 40 centavos, por los ejemplares atrasados desde el número 172 , sin el artículo «Magdala», para incrementar sus ventas. 
Por estas presiones Clorinda Matto de Turner tuvo que renunciar a la dirección del periódico en julio de 1891.

El 10 de junio de 1891, el obispo de Huánuco levantó la prohibición de la lectura de El Perú Ilustrado. El 31 de julio, también retiró la censura el obispo de Arequipa, Juan Ambrosio Huerta.

En una carta dirigida al arzobispo, la exdirectora de El Perú Ilustrado declaró no tener responsabilidad en este suceso, pues cuando se publicó esa edición, ella no pudo ir a la imprenta por encontrarse enferma.

Por uno de aquellos errores inconscientes que frecuentemente ocurren en las oficinas de los periódicos, apareció en nuestro número 172 el artículo que lleva este título, y que, publicado en La Razón de Montevideo, nos fue enviado en recorte que reservábamos en nuestra carpeta para refutarlo, pues, no obstante de ser puramente fantástico, notorias y comprobadas son nuestras convicciones religiosas y es la primera vez que ocurre esto, debido en gran parte a varios días de enfermedad de la directora sin que los propietarios del semanario tengan participación alguna.

Hacemos esta rectificación con la hidalguía que impone la honrada labor del periodismo.

Nota de la dirección (El Perú llustrado, 6 de setiembre 1890, p. 714).

Según Clorinda Matto, durante los días que estuvo ausente, el cuento de Coelho Netto fue insertado sin su conocimiento por un empleado de la imprenta, que fue despedido. En este incidente Clorinda Matto declaró no estar en contra de la religión católica; indicaba además haber insertado muchas veces en El Perú Ilustrado imágenes de sacerdotes, historias bíblicas y comentarios de las autoridades eclesiásticas.

A pesar de que la escritora hizo su descargo, tuvo que dejar la dirección de la publicación. En su lugar, se hizo cargo de la revista el propietario Peter Bacigalupi, quien criticó a su antecesora por todo lo sucedido. El 7 de julio de 1891, fue retirada la excomunión mediante un decreto del Arzobispado.

Palacio Arzobispal de Lima, 7 de julio de 1891

Vistas las razones expuestas en el presente recurso; y teniendo en consideración la formal protesta hecha a nos y a los demás ilustrísimos ordinarios de la república, por don Pedro Bacigalupi, en la que no ofrece no editar en su periódico o semanario El Perú llustrado nada contrario a Dios, a la religión católica, ni a la moral; y creyendo suficiente el tiempo transcurrido de la prohibición de su lectura para purgar la falta, por la que fue censurada; venimos en levantar esa censura, que en 3 de setiembre del año próximo pasado impusimos al referido semanario El Perú Ilustrado; quedando únicamente censurada y prohibida la lectura del número 172, en el que se ofende a 
la divinidad de Nuestro Señor Jesucristo en el artículo impío inserto en él bajo el rubro de «Magdala» del que se abstendrán los fieles sujetos a nuestra jurisdicción. Hágase saber y trascríbase a quienes corresponda.

El arzobispo de Lima

Martínez, secretario

Además de la excomunión, El Perú Ilustrado tuvo que hacer frente a la denuncia fiscal. Fue el famoso y cuestionado agente fiscal Amat y León quien, paralelamente a la excomunión, denunció el artículo de Coelho Netto. Ya era conocido que Amat y León simpatizaba desde siempre con la causa católica. En 1893, el semanario La Tunda lo acusó de favorecer a la causa católica, pues, según la denuncia, Amat y León fue en algún momento administrador del diario católico El Deber (La Tunda, 27 de mayo de 1893).

El caso «Magdala» fue comentado por muchos diarios. Fue un tema de polémica entre la prensa católica y la prensa liberal. Asimismo, dejó al descubierto el poder de la Iglesia en asuntos de prensa. Se pudo ver también que el Estado intervino en apoyo de la Iglesia a través de la denuncia llevada por el agente fiscal Amat y León.

En este conflicto la prensa liberal se solidarizó muchas veces con Clorinda Matto de Turner, pero no pudo hacer nada más que eso. El poder de persuasión de la Iglesia católica en un tema en el cual tenía plena competencia por determinarlo así la ley de imprenta lo hacía un tema ajeno a la discusión de la prensa.

\section{La Equitativa (1892-1895)}

A pesar del escándalo ocasionado por el cuento «Magdala», Clorinda Matto de Turner continuó con sus proyectos. La formación de la primera imprenta administrada y gestionada por mujeres fue uno de sus nuevos anhelos. Así nació La Equitativa.

Circula la noticia de que, de la imprenta La Equitativa que gira bajo la razón social Matto Hermanos, saldrá próximamente, convertido en diario, el semanario o bisemanario titulado El Deber que publicaba en los últimos años el presbítero, doctor don Alejandro Belando y Bandini. No sabemos si el diario continuará la numeración del periódico anterior o comenzará una nueva.

Según afirman otros, el doctor Belando ha vendido su propiedad sobre la cabeza o título El Deber a una empresa particular que se propone suprimir de dicho periódico la parte religiosa, al transformarlo en diario, para dejarle solo el carácter político y literario que también tenía antes. 
Por último, se nos dice que ha circulado un aviso-prospecto sobre $E I$ Deber, pero nosotros no lo hemos visto (El Eco de Lima, 10 de marzo de 1892).

De los talleres de esta imprenta, salió publicado el 17 de setiembre de 1892, el prospecto de Los Andes, bisemanario fundado por Clorinda Matto. Los talleres de La Equitativa estuvieron ubicados en la calle Áncash 19, frente al convento de San Francisco. Posteriormente se mudaron a la calle Calonge (Cornejo, 2006, p. 268).

La aparición de Los Andes fue comentada por otros periódicos, con cierta expectativa.

Asegúrase que la imprenta La Equitativa, traída recientemente del extranjero e instalada en la calle de Desamparados, es obsequio hecho por el general Cáceres a la señora Clorinda Matto V. de Turner.

Felicitamos a la agraciada por la importancia y la significación del regalo, y al obsequiante por el acierto que tuvo al elegir una imprenta para agasajar merecidamente a la ilustrada novelista cusqueña ( $E$ I Eco de Lima, 10 de marzo de 1892).

Sobre la historia de este periódico, Clorinda Matto se refirió en una carta escrita a su amigo y maestro Ricardo Palma, el 9 de enero de 1893.

En setiembre fundé Los Andes, periódico destinado a provincias, donde ha tenido una acogida admirablemente satisfactoria. Ya usted sabe las evoluciones políticas y el cómo hoy el partido del general Cáceres se ha impuesto. La unión de Rosas y Valcárcel es una burla que no ofrece consistencia y aquí «nadie» duda de que Cáceres será el sucesor honrado y valiente. Como usted comprenderá, Los Andes sirve al partido de Cáceres al que yo y mi familia hemos estado afiliados desde 1882, en que comenzó a ser figura política, sin que nunca hubiésemos variado de opinión. Cuando fundé el periódico, compadre, hice de cuenta que salía a la calle en aguacero y que era inevitable el mojarse, mucho menos acá donde los paraguas no se usan. Ya me han dicho zamba canuta porque dije que la ruina del país se debía a don Manuel Pardo, a esa secreta alianza con Bolivia y que la miseria de hoy era el legado del partido de los negros recuerdos. Sigo adelante sin levantar moño. Ya los venceré con la constancia, con la verdad y con el patriotismo (Arango-Keeth, 2012, p. 196).

Sus palabras demuestran un gran optimismo y una creencia firme en sus principios. Todo esto pronto se estrellaría con la realidad. Escribir y meterse en política fue desventajoso para las mujeres de esta época, pues se ponían al mismo nivel de los hombres, dentro de un terreno dominado por ellos. 


\section{Los ataques de sus enemigos}

Desde la campaña de la Breña, Cáceres fue visto como un líder provinciano dirigiendo una tropa de indígenas mal uniformados. El escritor José Gálvez Barrenechea alguna vez recordó que los soldados de Cáceres fueron conocidos por oler a las tres p: pisco, pezuña, pólvora (Gálvez, 1921, p. 255).

El Partido Constitucional fue visto como un grupo de indígenas desadaptados, con uniforme y que no hablaba bien el castellano. La imagen del soldado era la del ignorante que no sabía leer ni escribir, que se emborrachaba y causaba escándalos todo el tiempo.

De esta manera fueron vistos los colaboradores de Cáceres. Así, Clorinda Matto se transforma en «Clor-india» o «Clorenda»; su nombre será escrito y mal pronunciado. La prensa anticacerista, promovida por la oposición al Gobierno de Cáceres y Morales Bermúdez, lanzó insultos racistas contra la escritora. Aquí se menciona a varios periódicos como El Bisturí, El Barbero y la Falsa Tunda.
Mi plata vieja jamona
A costa de mis dineros
ipublicas hojas inmundas!
$Y$ echas a los basureros
Bisturíes y barberos
Y falsificadas tundas.
No me adules, mula zarca,
la más grande entre las grandes
que pastan en la comarca:
yo lo que quiero es tu arca,
no tu pasquín de Los Andes.
(El Chispazo, 29 de abril de 1893).

En la sección titulada «Pequeñeces» del semanario La Idea, aparecen constantemente varos insultos racistas contra la escritora.

El club Vanguardia piensa abrir un concurso para estudiar el mejor tinte que vuelva negras las patillas blancas del general.

Premio: una de las novelas realistas de la señora Matto.

(La Idea, 3 de noviembre de 1892).

\section{Pequeñeces}

Los editoriales de Los Andes:

Dilución de servilismo, procacidad, estolidez y... quechua.

(La Idea, 24 de noviembre de 1892). 


\section{Pequeñeces}

En Los Andes, nos dice un suscritor, que leyó esta frase del discurso del joven (de 40 años) Garrido Mendivil:

¡Aca... chisun!

Al oírla, recordó conmovido el general, el olorcillo de los soldados de la Breña...

Quechua, por quechua, ilustre escritora realista!

(La Idea, 24 de noviembre de 1892).

\section{Pequeñeces}

Futura novela realista de la señora Matto:

La servilleta de la Rábida.

(La Idea, 22 de diciembre de 1892).

\section{Pequeñeces}

Nueva novela realista de la señora Matto:

El gran proceso de la legislatura de 1892.

Ni Aves sin nido, ni Índole, ni La servilleta de la Rábida.

(La Idea, 14 de enero de 1893).

En el semanario político, satírico e ilustrado La Cachiporra, aparecido desde diciembre de 182, encontramos versos como estos.

Romero y flores

Tú siempre serás, querida, por tu cara estrafalaria, farolillo de botica;

por tu cuerpo, boticaria; por eso todos conocen, al saber tu afán nocturno, que no eres torno, Clorindia, sino Clorindia de Turno.

(La Cachiporra, 15 de diciembre de 1892).

La escritora es llamada «Clorindia de Turno», resaltando su carácter indígena y su apoyo al gobernante de turno.

Los mayores insultos Ilegarían del semanario El Leguito Fray José, publicación aparecida desde febrero de 1893, y La Tunda, grandes enemigos de Cáceres y el Partido Constitucional.

En 1893, el director de El Leguito Frai José, Estanislao Bravo, y uno de sus trabajadores fueron atacados en abril de ese año. La publicación fue clausurada en junio de 1893. También Manuel Belisario Barriga, director de La Tunda, sufrió varios atentados contra su vida por parte de los seguidores de Cáceres. 
En El Leguito Frai José, una de las secciones más satíricas de este periódico era «Cordonazos». Allí se criticaba a los partidarios de Cáceres. Al referirse a Los Andes, se le señaló como un periódico escrito por ignorantes.

\section{Cordonazos}

Un literato de a ciento en carga consultaba a otro ídem.

- Hasta con $h$, ¿qué parte de la oración es?

- Sustantivo, contesta el interrogado.

- ¿Y asta sin $h$ ?

—Adverbio, ¡hombre!, ¿qué, no lo sabía usted?

Después de un momento, rascándose la cabeza dice el mismo:

- Pienso escribir para Los Andes de doña Clorenda Mato.

(El Leguito Frai José, 19 de mayo de 1893).

En La Tunda, semanario anticacerista publicado por Manuel Belisario Barriga desde enero de 1893, encontraremos:

\section{A destajo}

La de las Aves sin nido

Buscando siempre alguna ave...

Al compás de ese quejido

Con que destroza el oído

Desde que le falta clave...

(La Tunda, 4 de marzo de 1893).

La amistad entre Matto de Turner y el general Andrés A. Cáceres era bien conocida por todos, por eso siempre se sugirió malintencionadamente que existía algo más. Esto fue publicado en el semanario La Cachiporra, donde se sugiere una extraña relación entre el héroe de la Breña y la escritora.

Clorinda del alma mía responde a tu enamorado:

a ti te han dado a la imprenta

o a ti la imprenta te han dado...?

(La Cachiporra, 15 de diciembre de 1892).

En el semanario El Cáustico, dirigido por Rodrigo Nicolás Herrera, publicado desde abril de 1893, se sigue atacando a Matto de Turner:

\section{Chismografía}

Clorinda la de las aves

Tiró... con el general

Un cachito. Ya lo sabes, 
Y una copa de cordial.

(El Cáustico, 13 de abril de 1893).

Otro tipo de insultos contra Clorinda Matto de Turner fueron dirigidos a su obra literaria. Matto fue muy valorada por los literatos de la generación romántica del siglo XIX, y fue amiga de Ricardo Palma y el grupo que frecuentaron las veladas literarias.

Pedro Paz Soldán y Unanue, conocido por el seudónimo de Juan de Arona, detestaba a las escritoras, luego que Mercedes Cabello le arrebató el primer puesto del concurso convocado por el Ateneo de Lima con su novela Sacrificio y recompensa.

Este escritor, como muchos en su época, consideraban que escribir no era un oficio de mujeres y mucho menos hablar de política, pues este era un tema de conversación masculina que pertenecía a la esfera pública, mientras los temas femeninos estaban relacionados con la esfera privada, es decir, la mujer podría hablar y escribir de todos los temas domésticos y sentimentales.

En marzo de 1892, apareció un comentario publicado en El Chispazo, publicación dirigida por Juan de Arona.

\section{La Equitativa}

Con este nombre se ha abierto un nuevo establecimiento tipográfico en la calle de los Desamparados, en la misma en que moran, residen o despachan los pobrecitos que componen el Poder Ejecutivo, que como ustedes saben se mueren de toda clase de desamparo.

Hasta aquí no hay nada de particular.

Y aún podríamos decir con el otro, aludiendo a la nueva imprenta: ¡que haya un cadáver más que importa a Lima!

Pero es el caso que, según el prospecto y un muestrario de imprenta como de 20 páginas que se han repartido al público, el nuevo plantel de rechinar va a ser servido por... señoras.

Instintivamente hemos echado mano al frac y los guantes, lo que va a ser un embarazo para los marchantes que carezcan de estos adminículos, o que no estén de humor de ponérselos al ir a contratar una impresión.

Las otras imprentas se llamarán ahora, lógicamente servidas por señores.

Lo que va a desterrar de los talleres los géneros hombre y mujer. Desde que oímos hablar del proyecto de establecer una imprenta servida por mujeres... eso será en parte. 
Y volviendo a lo de señoras, que se vaya a otra parte. A hacer juego con lo de caballeros en las estaciones ferrocarrileras.

Admitiendo que todas las actuales o futuras tipógrafas de La Equitativa sean todo lo señoras que se quiera, una vez que entran a cajistas, deben guardarse para cuando vuelvan a su casa un tratamiento que, en el taller, produce el mismo mal efecto que en el mon épouse de los porteros de París, en donde la gente más encopetada dice ma femme.

No olvidar que un grande que es España se expresa de igual modo cuando habla de la suya: mi mujer.

Y que en el nobilísimo lenguaje de la Biblia se la llama mulier, mujer, a la mismísima María.

A menos que la fundadora de la nueva imprenta, nuestra distinguida amiga la señora doña Clorinda Matto de Turner, no tenga alguna razón particular que El Chispazo no alcanza ni a chamuscar.

El muestrario contiene toda la nitidez y variedad de letras que debe esperarse de una imprenta nueva.

Porque los tipos de plomo, como los de carne y hueso, tienen también su belleza del diablo.

No hay quince feos.

La idea de nuestra amiga es una novedad... cuando menos poética.

Y merece prosperar (El Chispazo, 12 de marzo de 1893).

Clorinda Matto quiso entablar una polémica con Juan de Arona, pero sus amigos le aconsejaron que no le hiciera caso. Sobre esto comentó la escritora con Ricardo Palma en una de sus cartas de $1893^{3}$.

Aquí no falta perro que ladre de envidia. Juan de Arona ha estado machacándolo en El Chispazo. Yo le quise contestar, pero los amigos me han dicho que es darle suma importancia, porque el tal Chispazo no pasa de las murallas de Lima donde tanto conocen a Arona, el maldiciente por temperamento.

La escritora también fue acusada por sus detractores de haber plagiado obras de otros autores. En La Tunda se mencionó este tema.

\section{A destajo}

Y ya que hablo de esta poetisa.

3 Biblioteca Nacional del Perú. Colección Ricardo Palma. Carta de Clorinda Matto de Turner a Ricardo Palma. 
En el último número de Los Andes he leído una composición suya titulada «Dos autógrafos», que si no me equivoco de medio a medio es un plagio entero y verdadero de la otra de Enrique Heine a Inés.

Lo siento por la dueño del álbum en que se escribió el plagio ( $\mathrm{L} a$ Tunda, 19 de agosto de 1893).

Nótese que la escritora es tratada como «la dueño», nuevamente poniendo su género en oposición a su oficio. A esto también hace referencia una «pequeñez» del semanario La ldea.

\section{Pequeñeces}

Exclaman Los Andes:

«iTacna! la tierra de Vigil, de Zela, de Cáceres...». ¿Comería fuerte el redactor, macho o hembra?

(La ldea, 7 de enero de 1893).

\section{Pequeñeces}

La prima del 10 de noviembre

Madama la directora

del periódico Los Andes,

de mole... demoledora

y de propósitos... grandes:

esa Prima, aunque uste gima

la pena que llaman negra,

no tuvo nada de prima,

pero sí mucho de suegra.

(La Idea, 1 de diciembre de 1892).

Clorinda Matto no respondió a estos ataques y en todo momento mantuvo una línea circunspecta. Los editores de La Idea, uno de los semanarios que más la atacaron, negaron en todo momento llevar una campaña contra la escritora.

Pero nada hemos hallado que signifique, ni remotamente, una afirmación de la especie que ha desatado iras de la autora de Aves sin nido y de los Elementos de literatura para el bello sexo; verdad que, al hojear nuestros números, procedimos con rapidez que disculpan nuestras atenciones. He ahí la manera como sirven Los Andes a su público. Nuevo Don Quijote, el colega de La Equitativa, entretiene la soledad de su existencia, forjándose ataques imaginarios a su Dulcinea de espuelas y patillas.

Y es curiosa, por decir lo menos, la defensa de Los Andes (La Idea, 21 de enero de 1893). 
De la misma forma, La Tunda acusaba a la directora de Los Andes de iniciar una polémica con enemigos imaginarios.

\section{Burilando}

¿Por qué se nos ha venido encima, en su periódico Los Andes, la señora De Turner?

Manos blancas no hierran, señora, y, además, si usted en lugar de venir por encima lo hubiera hecho por abajo, ya le habríamos contestado...

Samanamú (La Tunda, 4 de marzo de 1893).

«Manos blancas no hierran»: esta frase encierra una doble moral machista. Se ataca a una escritora como si fuera un varón y se le niega la facultad de responder bajo los mismos términos masculinos, a riesgo de perder su femineidad.

Si bien Clorinda Matto fue tratada con el respeto que se merecía una señora, el hecho de intervenir en un espacio predominantemente masculino en cierta forma la masculinizaba. Como ha señalado Carolina Ortiz: «En este tránsito, mujeres como Clorinda Matto fueron apropiándose del saber que pertenecía básicamente al mundo masculino» (Ortiz Fernández, 2007. p. 383).

Esta era una gran limitación que tuvieron las primeras escritoras de esta época como Mercedes Cabello y Clorinda Matto. Sobre esto Fanny Arango ha señalado:

Durante su vida, Matto de Turner es sujeto de una triple discriminación dentro del espacio público: una por ser provinciana, otra por ser mujer y escritora y la tercera por ser un sujeto crítico dentro de la sociedad peruana patriarcal del siglo XIX (Arango-Keeth, 2012, p. 197)

También ha opinado sobre esto Emma María Mannarelli.

Mi impresión es que en la destrucción de las imprentas que poseían y dirigían las mujeres se expresan los amenazados poderes privados, en la medida en que estas simbolizaban la ampliación de las fronteras de la cultura pública, lo que a su vez suponía una redefinición de los poderes patriarcales (Mannarelli, 2002, p. 82).

\section{Haciendo leña del árbol caído}

Ser una de las principales partidarias del general Andrés A. Cáceres le ocasionó graves consecuencias a Clorinda Matto. En 1894, durante la entrada de las tropas de la coalición lideradas por Nicolás de Piérola, fueron saqueadas y destruidas la casa y la imprenta de Clorinda Matto. Por esta razón se vio obligada a abandonar el Perú y marchar al exilio en Argentina. 
El Leguito Frai José, uno de los periódicos anticaceristas clausurados por el decreto del 22 de junio de 1893, reapareció luego de la caída del Gobierno de Cáceres. Sus escritores tenían un profundo odio por los caceristas y los atacaron durante su camino al exilio. Un verso titulado «Aves sin nido», que imitaba a las rimas de Gustavo Adolfo Bécquer, decía:

\author{
Aves sin nido \\ Aves sin nido. Ya rotas \\ Las alas, no volarán, \\ Y así por la tierra van \\ Arrastrando sus derrotas... \\ Todas se calzan las botas, \\ todas se alistan a huir, \\ todas pretender lucir \\ sus garbos y sus donaires. \\ ¿Que ya empiezan a ir? \\ Pues velas y... buenos aires \\ Rompe testas. \\ (El Leguito Frai José, 1 de junio de 1895).
}

El Leguito Frai José publicó algunas caricaturas donde no dejaba de burlarse de la escritora. Se ve a Clorinda Matto llevando su periódico Los Andes como si fuera un delantal. En la mano sostiene una pluma. A su lado, aves con cabezas de conocidos personajes entre los que podemos distinguir a Andrés A. Cáceres, Justiniano Borgoño, Andrés Avelino Aramburú, entre otros, vuelan a su alrededor. Es una alegoría al exilio de Clorinda Matto en Buenos Aires.

La caricatura titulada «Triste final de los caceristas» muestra a Clorinda Matto con sus «aves sin nido» dando lastima. También se ve al director de La Opinión Nacional alquilando un bacín que lleva su nombre. Apareció en El Leguito Frai José el 22 de mayo de 1895.

Otra caricatura titulada «Matrimonio de alta política», aparecida en $E I$ Leguito Frai José el 29 de agosto de 1895, muestra a Clorinda Matto de Turner vestida de novia, en el altar, a punto de casarse con el director de $L a$ Opinión Nacional, Andrés Avelino Aramburú. Una clara alusión a la prensa cacerista. En la viñeta también aparece Cáceres, que actúa como sacerdote, y a un lado, como padrino, Antonia Moreno de Cáceres, que lleva un melón en la mano, haciendo alusión a la forma en que la llamaron sus enemigos: la Melonera o la Rabona Antuca.

A pesar de que Clorinda Matto estaba fuera del Perú, los ataques de sus enemigos continuaron por mucho tiempo más. 


\section{Cordonazos}

¡Lo que es el fenómeno psicológico de la asociación de las ideas! Por doña Fabiana me acuerdo de doña Clorinda.

Hablo de la señora Matto de Turner, la que andaba por Los Andes. ¿Aprendería esta el inglés que estaba estudiando para emigrar a los Estados Unidos si Cáceres perdía?

Tengo curiosidad por saberlo.

(El Leguito Frai José, 25 de abril de 1895).

Entre estos ataques lanzados durante su ausencia, se llegó a acusarla de haber recibido dinero del Gobierno de Cáceres.

\section{Cordonazos}

Dícennos que en los últimos días de la dictadura se entregó dos mil soles a la señora Matto de Turner como subvenciones adeudadas por la publicación de Los Andes.

Con razón se llevó el diablo al dictador.

Gastaba en periódicos lo que debía servir para dar de comer a su tropa.

¡Qué bárbaro!

(El Leguito Frai José, 10 de abril de 1895).

Otro de los rumores propalados por El Leguito Frai José acusaba a Clorinda Matto y su hermano el doctor David Matto de haber ayudado a los caceristas durante el ataque contra las tropas de la coalición en marzo de 1895.

\section{Cordonazos}

De la casa de los hermanos Matto (doña Clorenda y el médico) hicieron, como todo Lima sabe, nutrido fuego sobre los coalicionistas.

Esos hermanos hicieron subir a sus altos (calle de Calonje) a varios soldados caceristas, que, sin ser vistos, por las ventanas que dan al techo y agazapados en este, disparaban sobre la vecina torre de San Agustín y demás posesiones inmediatas, ocupadas por los restauradores.

Terminado el combate, una comisión fue a indagar quiénes habían sido los autores de tanto fuego, y, en pago de la cortesía y buenos modales de los comisionados, el doctor David Matto ha forjado la torpe e increíble especie de que estos le robaron 160 soles (EI Leguito Frai José, 4 de mayo de 1895). 
Durante el ataque a la iglesia de San Agustín, una de sus torres, que estaba siendo construida, fue seriamente afectada por disparos de artillería.

Se ha mencionado muchas veces que la casa de Clorinda Matto fue atacada por las tropas de la coalición nacional por haber sido colaboradora de Cáceres. Si lo que afirma EI Leguito Frai José era cierto, entonces el ataque a la casa de la escritora y la destrucción de su imprenta también fue motivado por haber sido utilizada para atacar a las tropas pierolistas.

Luego de la caída del Gobierno de Cáceres y sus seguidores, nadie defendió a la escritora. Incluso su amigo Ricardo Palma, en una carta a Lola Rodríguez de Tió, se refirió a la situación de su amiga Clorinda:

Clorinda Matto, después de la caída del Gobierno de Cáceres de quien era ella muy partidaria, ha creído que le convenía emigrar y hoy se encuentra en Buenos Aires. Mucho aconsejé a mi queridísima comadre Clorinda que no se mezclara en política. Pero me desatendió. Editó un periódico para defender algo que no admitía defensa (Palma, 1968, p. 31).

Palma creía que Clorinda Matto podría volver al Perú luego que la situación política se tranquilizara con la llegada de Nicolás de Piérola a la presidencia. Sin embargo, se equivocó y Clorinda Matto moriría lejos de su país en 1910.

Desde su exilio en Buenos Aires, Clorinda Matto vivió una vida holgada, donde pasó momentos difíciles; a pesar de eso, siguió con sus tareas literarias. Lejos de su tierra, lo que más extrañaba era a sus sobrinos y a su hermano, el doctor David Matto. Su visión acerca de la situación del Perú era pesimista y creía que la crisis del Perú continuaría con la llegada de Nicolás de Piérola al Gobierno. En una de sus $\operatorname{cartas}^{4}$ a Ricardo Palma, de mayo de 1895, la escritora comenta:

Bien me decía usted en una carta que ni Cristo compondrá nuestro país. La descomposición social es tan grave como la degeneración de la sangre. Desde esta distancia veo las cosas más claras y no cosecho más que la tristeza porque el futuro de nuestro país es peor que el de la Polonia.

\section{Reflexiones finales}

Las escritoras peruanas del siglo XIX fueron mujeres que tuvieron grandes obstáculos para dedicarse a este oficio. La vida de Clorinda Matto en Lima nos muestra cuáles fueron los prejuicios y dificultades que la rodearon por ser mujer.

4 Biblioteca Nacional del Perú. Colección Ricardo Palma. Carta de Clorinda Matto de Turner a Ricardo Palma. 
En el incidente «Magdala» se puede ver la condena pública de la Iglesia católica y la protesta de otras mujeres contra la escritora por haber dado a publicidad un escrito considerado anticlerical.

A pesar del apoyo de algunos colegas, quienes salieron en su defensa, la intervención de la Iglesia católica fue contundente. Era una época en que la Iglesia gozaba de gran poder, al haber tomado el papel de protectora espiritual de muchas mujeres que habían quedado desamparadas por la guerra.

Cuando Matto de Turner fundó la imprenta La Equitativa, fue otro momento conflictivo, al anunciarla como una imprenta atendida por damas. A fines del siglo XIX se consideraba que una mujer no podía hacerse cargo de este tipo de industria, reservada para los hombres.

Durante los años que vivió en Lima conoció de cerca los excesos cometidos por la pugna entre la prensa que representaba a los caudillos políticos. Cuando llegó a Lima, Clorinda Matto se dedicó a la vida literaria, y sobrevivió gracias a modestos trabajos y la protección de su hermano David. Luego del incidente de «Magdala» y la publicación de sus novelas, la escritora fue interesándose más en la política.

Esto le ganó muchos enemigos que luego la atacaron cuando un hubo un cambio del régimen político.

Siempre se ha idealizado a Clorinda Matto de Turner como una precursora del movimiento femenino en nuestro país. En la realidad, según el propio relato de la escritora, ella sobrevivió en el desamparo luego de quedar viuda. El negocio que le dejó su marido quebró debido a las deudas que le produjo la Guerra del Pacífico. Sobrevivió trabajando en un periódico de provincia, donde le pagaban muy poco.

El famoso incidente de «Magdala» que ha sido exaltado como un episodio polémico de su vida, no lo es en realidad, pues la escritora evadió en todo momento su responsabilidad en este acontecimiento y mostró sumisión frente al predominio del clericalismo de la época.

En el fondo, era una mujer de su época, que trató de incursionar en un mundo dominado por hombres. Tenía una profunda emoción social y gran optimismo. Creía en el proyecto político de Cáceres, pero fue víctima de la inestabilidad que se vivió luego de la derrota del Perú en la Guerra del Pacífico. 


\section{ANEXO 1. MAGDALA}

Brillaba el largo peristilo de mármol, iluminado por los candelabros romanos y por las trípodes griegas, donde de instante en instante vertíanse patenas de oro llenas de cinamomo y alve. Una fuente aromática borbotaba en un estanque de jaspe un chorro que lloraba y caía en hilo finísimo de cascada como lágrimas de flor. Subía ledo el humo de los incensarios y de instante en instante salía de entre las columnas del fondo un africano con escudo en la cabeza y lo vertía bruscamente, tapizando el mármol de rosas y de lirios de Ghilbóe.

Jóvenes de Samaria, vestida como sacerdotisas con el kithonel de seda color de oro, cayendo hasta las rodillas, el largo cinturón de lino, en los pies las babuchas salpicadas de topacios y sardónicas, y en la cabeza, oprimiendo los negros cabellos, la mitra igual a la de Isis, sentadas en mullidos cojines de lana de camello con los diminutos kennors hebreos al cuello, cantaban una serenata de amor lánguida y deliciosa; otras, acostadas con los pechos desnudos expuestos a la luz en una evidencia blanca y coralina, besaban los picos de las tórtolas, en alto y lujurioso solio, lecho en la forma, trono en la convención.

María de Magdala, desnuda, con un velo transparente apenas envuelto al vientre, sofocaba los precipitados movimientos de su moreno cuello, y ahogaba los continuos suspiros que le subían a la garganta. A su derecha y a su izquierda dos esclavas inmediatas $A$ su lecho la incensaban, $y$ atrás dos le hacían aire con enormes abanicos. Ella, sin embargo, distraída, poco se ocupa de lo que en torno de ella se agitaba; sus grandes ojos negros no se separaban del pórtico y el más mínimo movimiento del eunuco que guarda la entrada le agitaba un estremecimiento nervioso y su boca roja como la flor del cactus se entreabría como para desabrochar un beso.

Gemían las arpas cada vez más tristes y solo interrumpía aquel concierto melancólico el alerta áspero y duro del centinela que vigilaba en la torre de Makeros.

En el fondo del huerto donde se abrían los lirios y las rosas cantaban los cisnes apasionados.

Noche nupcial enervante y muelle, en la voz fatigada de los montañeses que trillaban los caminos aún caliente, habían un lánguido pedido de besos, el balido de las ovejas en medio del silencio era como un estribillo amoroso de ditirambo, todo participaba de la influencia del último mes, el fuerte, el cáustico, el abrasador mes del sol; en los vecinos montes de la ciudad los bárbaros Kamaneos conservaban las hogueras y de cuando en cuando un grito agudo cruzaba silbando, como el graznido de las cigüeñas que huyen en las borrascas; era el evohé salvaje de los pastores. 
Un gong vibró afuera, en el jardín, entre los mirtos en flor, las samaritanas dejaron caer los Kinnors, los abanicos y los incensarios pararon, todas las miradas volviéronse hacia la sombra: Magdala llevando la mano al pecho, inclinose ansiosamente para ser la primera en divisar al amado... Hízose un silencio grave, solo lo interrumpió el eunuco que vigilaba entre las dos columnas, agitando por tres veces su largo alfanje y diciendo con una voz gangosa como la de los fariseos:

-El tetrarca!

— ¡No! ¡No! —gritó imperiosamente Magdala—. ¡No lo recibo! ¡No! ¡Corran las cortinas! Corran las cortinas! No lo recibo! No lo recibo!

En el mismo instante, desenrollose del techo una onda solferina rayada de oro, y el pórtico cerrose por una gruesa cortina bordada en relieve con un paisaje de Moab, campo, río y un cielo sin color por donde volaba una bandada de águilas.

— ¡No...! ¡No...! — continuó la Magdala-. No lo recibo.

Y nerviosa y frenética, dejose de nuevo caer en su espacioso lecho, ordenando con un gesto a las jóvenes de Samaria y a las esclavas que volviesen a empezar. Sonaron los kinnors y los abanicos y los incensarios pusiéronse de nuevo en movimiento.

María de Magdala no pudo contener sus lágrimas — la luna estaba muy alta, y se había extinguido las voces en el vecino campo- la ciudad se había cerrado... y él, su amado, lejos tal vez en un sitio inculto o entre la plebe que habitaba la margen del lago de Generzareth.

Iba a levantarse, para salir tal vez, sin destino, sola, por medio de los prados, en busca del preferido de su corazón, cuando el gongo vibró de nuevo.

Irguiose, el cendal que cubría su vientre aflojó y cayó enrollado a sus pies, formando un pequeño pedestal de gasa, y ella desnuda, firme, con la mirada fija en la pesada cortina, esperó que el eunuco acudiese, y anunciase al recién venido.

No fue larga su espera. La cortina onduló, y la cabeza negra del centinela, surgió de entre las franjas, lanzando hacia el gineceo él anunció:

— ¡Jesús!

El pudor la venció. Inclinose rápida para coger la gasa y se envolvió en un instante y riendo se dejó caer en los cendales del ancho lecho y encogiéndose cubriose dejando apenas la cabeza libre en la que se manifestaba la ansiedad y cuyos ojos brillaban con fulgor de astros.

Volvió a ondular de nuevo el pesado paño de peristilo y Jesús se presentó entre las blancas columnas de mármol de Pharos. 
Lo envolvía un amplio oba rayado de púrpura, tenía la cabeza desnuda y calzaba sandalias de aguda punta, caíanle sobre los hombros relucientes bucles de su negro cabello y su espesa barba le sombreaba el pecho, tenía la túnica cribada de las espinas del camino y ostentaba en su diestra mano un ramo de elvendro. La fuerte luz del interior le hirió la vista obligándole a velar con sus párpados la dulce mirada, en la cual a fuerza de comunicarse con el cielo se notaba cierto brillo profético. Irguió la cabeza y desconsolado y triste quedó un instante contemplando el velarium corrido que escondía la luna y velaba las estrellas.

— ¡Corran el velarium! ¡Corran pronto el velarium! — gritó Magdalena, siempre encogida, pero sin apartar los ojos del Nazareno.

Como por encanto desapareció súbitamente el falso techo y el cielo tranquilo, tachonado de estrellas, con la luna llena, blanca y resplandeciente en el zenit sustituyose a la seda; los perfumes silvestres tan amados del profeta de los sencillos de corazón entraron profusamente. Él se detuvo para contemplarlo sereno, dulce, sonriente y si la voz de la enamorada no le hubiese llamado, de seguro que habría permanecido de pie mirando la noche y el país de su Padre, lejos en la azul esfera sembrada de astros.

一¡Jesús!

El Nazareno se volvió y confiado en la fortaleza de su corazón se adelantó hasta el enorme lecho de María. Allí se detuvo y sus ojos fueron poco a poco languideciendo denominados por la luz ardiente de los de la concubina.

Un ruido se sentía a su alrededor, caía por momentos una voluptuosa sombra, se dio vuelta para mirar y se encontró que la sala estaba desierta, todos habían desaparecido, solo María de Magdala, encogida, lo miraba sonriente, obligándolo a no separar sus ojos de ella.

Una mano invisible extinguía los trípodes de los ángulos.

—iJesús! —dijo Magdalena, con una especie de arrullo, extendiéndole los desnudos brazos en un lánguido gemido.

Tomole ambas manos, atrájole cariñosamente e iba a besarle en la boca, cuando un rugido feroz estalló en el silencio.

Ambos se estremecieron.

— ¡Jerusalén! ¡Jerusalén! —repercutió la voz lejana_-... Has de ser eternamente esclava... Esclava... Sierva has de ser por toda la eternidad, pantano y lodo quedarás. ¡Jerusalén! ¡Jerusalén! ¡Llora si aún tienen lágrimas!

—Es la voz de Isaías que gime maldiciones... —-murmuró Jesús, trémulo de emoción. 
-No, amor... No es eso... Cerca de aquí queda la cárcel de Herodes... En el fuerte de Makeros, esos gemidos son de allí... Es la voz del Bautista. Quédate... Ocultémonos en nuestro amor, ¡bésame! ¡Bésame! ¡Bésame!...

Pero la voz se oyó de nuevo:

- ¡Profecía de los fuertes! ¡Profecía de los fuertes! Jerusalén, has de ser el prostíbulo del mundo... Vende las hijas, púdrete, miserable úlcera, déjate roer por los gusanos. Charca, lodo heces... Muere, jseca al sol tu estercolero!

- ¡No! Y en un movimiento brusco Jesús se arrancó de los brazos de la concubina, y loco, alucinado, presa de un santo delirio, se lanzó hacia afuera y desapareció en medio de las sombras de la noche, mientras se oía aún el eco lejano que repetía:

—¡Jerusalén! ¡Jerusalén! ¡Tierra de los fuertes, muere!

Y la Magdala, desnuda, mirando hacia su frente, extendió el blanco brazo en dirección de Makeros y en una explosión de lágrimas, gritó trémula de odio, mesándose los cabellos húmedos de bálsamo:

— ¡Ladra! ¡Ladra! ¡Perro de Israel!

Y cayó de bruces, retorciéndose y balbuceando el nombre amado y suave de Jesús. 


\section{ANEXO 2}

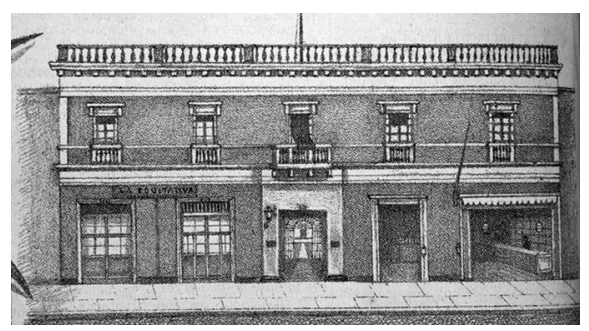

Local de La Equitativa. El Perú llustrado, 14 de febrero de 1891, p. 1002.

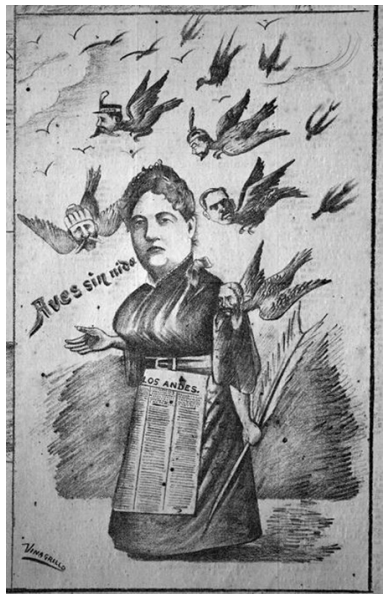

«Aves sin nido». El Leguito Frai José, 22 de mayo de 1895, p. 3.

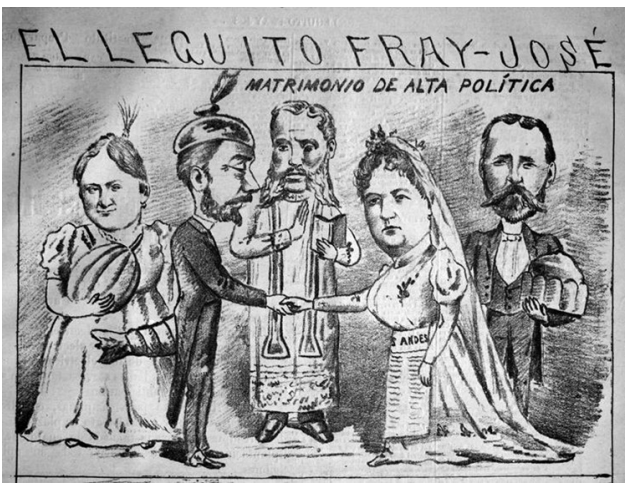

«Matrimonio de alta política». El Leguito Frai José, jueves 29 de agosto de 1895, p. 3. 


\section{REFERENCIAS BIBLIOGRÁFICAS}

Arango-Keeth, F. (2012). La construcción del sujeto autobiográfico, histórico y político en la correspondencia epistolar de Clorinda Matto de Turner (Cartas a Ricardo Palma, 1883-1908). En S. Guardia (Ed.), Escritoras del siglo XIX en América Latina (pp. 187-203). Lima: Centro de Estudios en la Historia de América Latina.

Berg, M. G. (2000). Presencia y ausencia de Clorinda Matto de Turner en el panorama literario y editorial peruano. En I. Arellano y J. Mazzotti (Eds.), Edición e interpretación de textos andinos: Actas del Congreso Internacional (pp. 211-230). Madrid: Iberoamericana.

Cornejo Quesada, C. (2006). Presencia e imagen del periodismo femenino en el siglo XIX. Revista Cultura. Asociación de docentes de la Universidad de San Martín de Porres, 20(20), pp. 241-276.

Ferreira, R. (2006). Clorinda Matto de Turner: infatigable obrera del pensamiento. Crónicas urbanas: análisis y perspectivas urbano regionales, 11, pp. 111-124.

Forgues, R. (marzo de 1993). Narradoras peruanas del siglo XIX y emergencia de una escritura femenina. Socialismo y participación, 61, pp. 55-58.

Gálvez, J. (1921). Una Lima que se va. Crónicas evocativas. Lima: Euforión.

Mannarelli, M. E. (2002). La destrucción de las imprentas, el poder de los sexos y el proceso de secularización en el Perú. 1895-1925. Diálogos en Historia, 3, pp. 81-93.

(julio de 2002). El poder de los sexos: la destrucción de las imprentas. Libros \& Artes. Revista de Cultura de la Biblioteca Nacional del Perú, 2, pp. 5-7.

Martin, C. E. (2010). Cien años después. La literatura de mujeres en América Latina: el legado de Mercedes Cabello de Carbonera y Clorinda Matto de Turner. Lima: Fondo Editorial de la Universidad de San Martín de Porres.

Ortiz Fernández, C. (2007). El pensamiento político de Clorinda Matto de Turner: pensamiento social peruano y latinoamericano. Investigaciones sociales. Instituto de Investigaciones Histórico Sociales de la Facultad de Ciencias Sociales, UNMSM (18), pp. 381-400.

Palma, R. (1968). Diecisiete cartas inéditas con otras editas cambiadas con Doña Lola Rodriguez de Tío (1894-1907). Lima: Universidad Nacional Mayor de San Marcos. 
Portugal, A. (2010). El periodismo militante de Clorinda Matto de Turner. Alicante: Biblioteca Virtual Miguel de Cervantes. Recuperado de http://www. cervantesvirtual.com/obra-visor/el-periodismo-militante-de-clorindamatto-de-turner/html/

Recepción: 26/1/2018

Aceptación: 2/3/2018 